\title{
Consistency and Predictive Ability of Fertility Preference Indicators: Longitudinal Evidence from Rural India
}

By Tarun K. Roy,

R.K.Sinha, Michael

Koenig, Sanjay K.

Mohanty and

Sangram K. Patel

Tarun K. Roy, current-

ly an independent con-

sultant, was director

and senior professor,

International Institute

for Population

Sciences, Mumbai,

India, when this study was conducted.

R. K. Sinha is professor and head, Depart-

ment of Extra Mural

Studies; Sanjay K.

Mohanty is reader,

Department of Fertili-

ty Studies; and San-

gram K. Patel is re-

search scholar-all at

the International

Institute for Popula-

tion Sciences. Michael

Koenig is professor,

Department of Popu-

lation and Family

Health Sciences,

Bloomberg School of

Public Health, The

Johns Hopkins Univer-

sity, Baltimore, MD,

USA.

\begin{abstract}
CONTEXT: Ideal family size and desire for an additional child are the two most commonly used fertility preference indicators. However, little is known about the consistency over time of responses to each measure, the consistency between the two indicators or the predictive value of these indicators in India.
\end{abstract}

METHOD: Longitudinal data from the 1998-1999 National Family Health Survey and a follow-up survey conducted four years later were analyzed to determine the consistency of responses to the two fertility preference indicators (both over time and between indicators) and to determine whether baseline responses were associated with subsequent fertility, unwanted births and contraceptive use.

RESULTS: Responses on the measure of ideal family size were consistent at the two time points for 53\% of nonsterilized women. Eighty-two percent of women who explicitly said in 1998 that they did not desire more children responded identically in 2002, although about half of these women had given birth in the intervening period. The indicators were associated with each other: Among women with at least one son, $79 \%$ of those who had attained or surpassed their ideal family size said they wanted to stop childbearing, compared with $18 \%$ of those who had not. Both indicators predicted future fertility, unwanted births and contraceptive use, particularly among women who had a son.

CONCLUSION: Both indicators are useful in understanding future fertility behavior. As the prevalence of son preference declines in India, the predictive ability of the indicators is likely to improve.

International Family Planning Perspectives, 2008, 34(3):138-145

Information on fertility preference is an integral part of any demographic survey, and preference indicators have long been used to determine the demand for children in a population. ${ }^{1}$ Two of the most widely used measures for assessing fertility preference are ideal family size and the desire for an additional child.

Studies have been conducted in both developed and developing countries to examine the effectiveness of these indicators, particularly desire for an additional child. Given the usefulness of longitudinal research in this context, most studies have involved interviewing a group of women at two points in time..$^{2-11}$ In addition, a few studies have tried to provide evidence at the macro level, using crosssectional data. ${ }^{12}$ Most of these studies examined the extent to which the desire for more children predicts future fertility. Studies conducted in Korea, Malaysia, Nigeria, Sri Lanka, Taiwan and the United States have confirmed that this indicator is suitable for predicting whether a woman will have future births, although its effectiveness depends on, among other factors, whether couples' fertility intentions are examined or only women's.

Recently, the preference indicators have been used extensively to determine women's unmet need for family planning. ${ }^{13,14}$ (The concept of unmet need, in turn, has become a potential tool for promoting family planning as well as for evaluating family planning programs.) The indicators are also used to gauge the prevalence of unwant- ed births in a population; ${ }^{15-17}$ for example, data on women's desires for additional children can be used to classify births (or current pregnancies) as wanted or unwanted. $^{18}$

A number of factors may influence the predictive value of the fertility preference indicators in India, the site of the current study. Because women have low status in Indian society, their ability to make important family decisions is limited. The cultural preference for sons over daughters may be an obstacle to women's ability to adhere to their fertility decisions. In addition, it is possible that household time pressures, the high level of illiteracy and a lack of understanding of the value of survey data may result in casual or inaccurate responses to survey questions. However, very little is known about the effectiveness of the two indicators in predicting fertility behavior in India. ${ }^{19}$

Moreover, the extent to which individuals' responses to one preference indicator are consistent with their responses to the other-and whether including both indicators in demographic surveys is preferable to including just one of them-is not clear. This issue is of particular concern to the developers of large-scale demographic surveys, who face considerable pressure to obtain data on a large number of topics. Information on the relative utility of the two preference indicators can help guide survey designers in their efforts to maintain the questionnaires at a reasonable size. 
It is also important to note that each indicator has its drawbacks. Collecting information on ideal family size can be relatively complex, and it is often difficult to get objective responses. The standard survey procedure requires that questions be asked verbatim and not be rephrased. But because questions about ideal family size are hypothetical in nature, respondents-particularly those who are illiterate or have little education-often have difficulty comprehending them. Hence, the possibility that the interviewer will deviate from the standard wording-thus reducing the validity of the data-is substantial.

The other preference indicator, desire for an additional child, requires a very simple question. But this is not necessarily an advantage. Respondents may put insufficient thought into their replies when asked questions that require a "yes" or "no" answer.

In this paper, we attempt to extend current knowledge in the context of India, using longitudinal data that provide a variety of information on the fertility intentions and behavior of a group of women at two points in time. We examine the consistency of the two preference indicators and their ability to predict future fertility, unwanted births and contraceptive use.

\section{DATA AND METHODS}

The data used in this article are from a longitudinal study conducted in rural areas of three states in India: Bihar, * Maharashtra and Tamil Nadu. These states were chosen to represent a range of socioeconomic and demographic contexts. The study population consisted of women who were interviewed for the National Family Health Survey (NFHS2), a large demographic survey conducted in 1998-1999, and were reinterviewed in a follow-up survey approximately four years later. The follow-up survey was intended to assess any changes in the quality of family welfare program services in the study regions as well as the program's effects on women's use of birth spacing methods. ${ }^{20}$ For simplicity, we refer to the surveys as having been conducted in 1998 and 2002.

The NFHS-2 revealed that Tamil Nadu had achieved the replacement level of fertility, with a total fertility rate of 2.2 births per woman. Total fertility was only slightly higher in Maharashtra (2.5), but the rate in Bihar (3.5) was among the highest in India. Substantial proportions of married women were using a method of contraception in Tamil Nadu (52\%) and Maharashtra (61\%) in 1998; sterilization was the mainstay of the program in both states, accounting for $86-88 \%$ of contraceptive use. ${ }^{21,22}$ In contrast, only $25 \%$ of married women in Bihar were using a method; sterilization, again, was the primary means of contraception (82\%). ${ }^{23}$ Among the three states, the preference for sons over daughters was lowest in Tamil Nadu. $^{24}$

Women were eligible for the follow-up study if they had participated in the NFHS-2 and, at the time of that survey, were married, aged 15-39 and living in a rural region of the relevant states. The follow-up survey was planned while data collection for the NFHS-2 was in progress; in fact, in Maharashtra and Tamil Nadu, NFHS-2 respondents were invited to participate in the follow-up study during administration of the first study (this could not be done for Bihar).

The response rate for the follow-up survey was $85 \%$. The main reasons for nonresponse were that women were unavailable or had moved away. Fewer than 1\% of the target sample refused to be interviewed. The total sample size was 6,303 women, including 3,666 from Bihar, 1,520 from Tamil Nadu and 1,117 from Maharashtra. The socioeconomic characteristics of women in the 2002 sample were similar to those of women in the original NFHS-2 sample in each state. ${ }^{20}$

The question used to collect information on ideal family size was the same in the two surveys. Women who did not have any children were asked, "If you could choose exactly the number of children to have in your whole life, how many would that be?" Women who already had children were asked, "If you could go back to the time you did not have any children and could choose exactly the number of children to have in your whole life, how many would that be?" Respondents were asked about their ideal family size regardless of whether they or their husbands were sterilized. We assessed the agreement between women's responses in 1998 and their responses in 2002. Because we expected the agreement to be better among women who had completed their family, we analyzed responses separately for sterilized women and for nonsterilized women. We also examined responses by region and by whether women gave birth between surveys.

Two methodological issues should be noted concerning the consistency over time of women's responses on this indicator. First, given the time gap between the two surveys in this study, a change in a woman's ideal family size could reflect the influence of broad social factors, such as increases in education, rather than individual-level changes in fertility preferences. However, the four-year gap between surveys is likely not long enough for widespread changes in ideal family size to occur among the rural population, and there was little evidence of improvement in the education level of these women during the intersurvey period. ${ }^{20}$ Second, ideal family size may be affected by rationalization. 1,12,25,26 When individuals' actual family size surpasses their ideal family size, they tend to adjust the latter so that it is close to the actual size of their family; this allows them to avoid giving the impression of having unwanted children (the number of children in excess of the ideal is generally regarded as unwanted). ${ }^{18}$ This phenomenon results in a systematic bias in responses, and contributes to inconsistency in the measurement of fertility desire.

The question for the second fertility indicator, the desire for an additional child, was asked of married women who had not been sterilized and whose husbands had not

*In 2000, Bihar was divided into two states, Jharkhand and Bihar. In this article, Bihar refers to the combined, pre-2000 state. 


\begin{tabular}{|c|c|c|c|c|c|c|c|c|}
\hline \multirow[t]{2}{*}{$\begin{array}{l}\text { Sterilization } \\
\text { status }\end{array}$} & \multicolumn{2}{|l|}{$\begin{array}{l}\text { Mean ideal } \\
\text { family size }\end{array}$} & \multicolumn{4}{|c|}{ Change in ideal size } & \multicolumn{2}{|c|}{$\mid \begin{array}{l}\text { Non- } \\
\text { numeric } \\
\text { response }\end{array}$} \\
\hline & 1998 & 2002 & Decrease & None & Increase & Total & 1998 & 2002 \\
\hline All women & $2.83(0.38)$ & $2.66(0.35)$ & $27.8(34.2)$ & $52.9(31.6)$ & $19.2(34.2)$ & 100.0 & 4.8 & 5.7 \\
\hline Nonsterilized & $2.97(0.39)$ & $2.78(0.36)$ & $29.9(35.5)$ & $49.3(29.0)$ & 20.8 & 100.0 & 5.5 & 7.4 \\
\hline Bihar & $3.34(0.34)$ & $3.11(0.32)$ & $37.1(36.0)$ & $38.0(28.0)$ & $24.9(36.0)$ & 100.0 & 6.6 & 10.3 \\
\hline Maharashtra & $2.30(0.35)$ & $2.25(0.36)$ & $17.9(23.7)$ & $68.8(52.5)$ & $13.3(23.7)$ & 100.0 & 4.5 & 1.8 \\
\hline Tamil Nadu & $2.06(0.25)$ & $2.03(0.19)$ & $14.0(18.0)$ & $74.0(63.9)$ & $12.0(18.0)$ & 100.0 & 2.3 & 0.1 \\
\hline Sterilized & $2.52(0.33)$ & $2.39(0.29)$ & $23.6(29.9)$ & $60.5(40.2)$ & 15.9 (29.9) & 100.0 & 3.2 & 1.8 \\
\hline Bihar & $3.14(0.29)$ & $2.85(0.27)$ & $35.2(34.4)$ & $46.4(31.2)$ & $18.4(34.4)$ & 100.0 & 1.7 & 3.8 \\
\hline Maharashtra & $2.44(0.27)$ & $2.33(0.25)$ & $24.4(27.1)$ & $58.6(45.8)$ & $17.0(27.1)$ & 100.0 & 4.5 & 1.4 \\
\hline Tamil Nadu & $2.02(0.23)$ & $2.03(0.21)$ & $12.3(15.3)$ & $74.8(69.4)$ & $12.7(15.3)$ & 100.0 & 3.4 & 0.1 \\
\hline
\end{tabular}

been sterilized. Women who were not pregnant were asked, "Would you like to have (a/another) child or would you prefer not to have any (more) children?" For pregnant women, the question was, "After the child you are expecting, would you like to have another child or would you prefer not to have any more?" Note that a woman who initially desires to have more children may no longer do so four years later, especially if she has given birth in the interim; in other words, fertility desire may change because of changes in a woman's circumstances (the number of children she has). Responses are likely to be more stable among women who do not desire more children; one might expect that most of these women would not give birth between the two surveys and would maintain their desire to avoid childbearing. As we did for ideal family size, we analyzed the consistency of responses between the two surveys. Because of the strong preference for sons in India, we assessed the consistency of responses separately for women who had a son in 1998 and those who did not.

We also examined the consistency between women's responses on the two indicators. If women's ideal family size was less than or equal to their actual family size, they were deemed to have an implicit desire to stop childbearing.

\begin{tabular}{|c|c|c|c|c|c|c|c|}
\hline \multirow[t]{2}{*}{$\begin{array}{l}\text { Implicit desire } \\
\text { subsequent birth }\end{array}$} & \multirow[t]{2}{*}{$\mathrm{N}$} & \multicolumn{2}{|c|}{$\begin{array}{l}\text { Mean ideal } \\
\text { family size }\end{array}$} & \multicolumn{4}{|c|}{ Change in ideal size } \\
\hline & & 1998 & 2002 & Decrease & None & Increase & Total \\
\hline All & 3,845 & 2.84 & 2.78 & $27.3(33.8)$ & $51.1(32.4)$ & $21.5(33.8)$ & 100.0 \\
\hline Implicit desire & 1,528 & 2.74 & 2.88 & $20.9(34.1)$ & $51.5(31.8)$ & $27.5(34.1)$ & 100.0 \\
\hline Birth & 760 & 2.80 & 3.02 & $18.4(34.2)$ & $48.4(31.6)$ & $33.2(34.2)$ & 100.0 \\
\hline No birth & 768 & 2.72 & 2.72 & $23.4(33.9)$ & $54.7(32.2)$ & $21.9(33.9)$ & 100.0 \\
\hline No implicit desire & 2,317 & 2.91 & 2.71 & $31.5(33.4)$ & $50.8(33.2)$ & $17.6(33.4)$ & 100.0 \\
\hline Birth & 1,728 & 2.93 & 2.76 & $30.1(33.5)$ & $51.4(33.0)$ & $18.5(33.5)$ & 100.0 \\
\hline No birth & 589 & 2.84 & 2.56 & $35.8(33.2)$ & $49.2(33.6)$ & $14.9(33.2)$ & 100.0 \\
\hline
\end{tabular}

Note:Sample limited to women who were not sterilized, and whose husbands were not sterilized, in 1998
Similarly, if they said that they did not desire to have another child, they were regarded as having an explicit desire to stop childbearing. We expected that women who had attained or surpassed their ideal family size would be more likely than those who had not to express an explicit desire to stop childbearing.

Finally, we assessed the preference indicators' ability to predict three dimensions of fertility and fertility behavior: future fertility, unwanted fertility and contraceptive use. Specifically, we examined the relationship between the preference indicators and whether a woman gave birth in 1998-2002, whether her first birth during that period was unwanted and whether she was using contraceptives in 2002 (assuming neither she nor her husband was sterilized.) Although some women had more than one birth in the intersurvey period-in Bihar, for example, $21 \%$ of women had two or more births during that time-we considered only the first birth, as our purpose was not to estimate the number of unwanted births but rather to examine the ability of the indicators to predict unwanted births in general

\section{RESULTS}

\section{Consistency of Responses}

As might be expected from the differences in fertility levels in the three states, mean ideal family size was smaller in Tamil Nadu (about two children) than in the other two states in 1998 and 2002, among both nonsterilized and sterilized women (Table 1). Among nonsterilized women, mean family size was largest in Bihar in both years (3.3 children in 1998 and 3.1 in 2002).

Overall, $53 \%$ of women gave consistent responses at the two time points on the measure of ideal family size. The correspondence was highest in Tamil Nadu; for example, $74 \%$ of nonsterilized women in that state had the same ideal family size in 2002 as they had had in 1998. In all, $69 \%$ of women in Maharashtra and 38\% of those in Bihar gave congruent responses. Agreement was higher among sterilized women (46\%) than among nonsterilized women (38\%) in Bihar, but the reverse was true in Maharashtra ( $59 \%$ vs. $69 \%$ ), and there was little difference between the groups in Tamil Nadu. Moreover, unlike in the other states, ideal family size was higher among sterilized women than among nonsterilized women in Maharashtra

To better clarify the relationship between responses in 1998 and those in 2002, we calculated the expected distribution of the difference between the two responses Here, we assumed that women's responses at the second time point were independent of (i.e, not associated with) their responses at the first, and that they followed the distribution observed at the first time point. The larger the deviation between the observed and the expected distributions, the greater the chance that the two responses are associated and not given independently.

The distribution of the difference in the responses at the two points of time differed from the expected distribution statistically, in all three states, among both nonsterilized 
and sterilized women ( $\mathrm{p}$-values not shown). Moreover, the pattern of deviation between the observed and the expected distributions was similar in all three states: In each case, the two responses coincided more often than expected, and the responses in 2002 were greater than those in 1998 less often than expected. Thus, when the two responses were not the same, women tended to have a smaller ideal family size at the second time point. This was particularly true for Bihar and Maharashtra. In Tamil Nadu, the ideal family size seems to have stabilized at two children; hence, the expected and actual proportions of responses that coincided at the two time points were high.

Some women gave nonnumeric answers when asked about ideal family size-for example, "it depends on God" or "as many as possible." These answers-which, in a way, show respondents' disinterest in or aversion to a planned family-were least prevalent in Tamil Nadu.

Another approach to understanding the consistency of the indicator is to examine responses according to whether women had an implicit desire to stop childbearing in 1998 and whether they subsequently had a birth. Women who had an implicit desire to stop childbearing in 1998 but gave birth during the intersurvey period may have rationalized the increase in their family size by reporting a higher ideal family size in 2002 than they had in 1998. In contrast, rationalization would not be relevant for women who did not have an implicit desire to stop childbearing. For example, a nulliparous woman who had an ideal family size of two in 1998 and who gave birth to two children during the intersurvey period would not need to rationalize her births.

As expected, ideal family size increased only among women who had an implicit desire to stop childbearing in 1998 and subsequently gave birth (Table 2). Among the other groups, mean ideal family size in 2002 was equal to or less than that in 1998. Findings were generally similar in separate analyses conducted for the three states (not shown).

We also assessed the consistency of the other indicator: women's explicit statements that they desired no more children. In general, women who had a son in 1998 and said at that time that they did not desire more children were consistent in their responses: In 2002, 82\% said they did not want any more children (Table 3). However, nearly half of these women gave birth during the intersurvey period, which can be considered incongruent with their stated desire to stop childbearing. If these women are excluded from the calculation, as well as those who did not

\footnotetext{
*Of the 565 women who had a son in 1998, stated at the time that they did not desire any more children and did not give birth between surveys (Table 3), 83\%, or 468, desired to stop childbearing at both time points and hence were consistent. These women represent $43 \%$ of the 1,084 women who had a son in 1998 and did not desire any more children.

tOf the 46 women who did not have a son in 1998, stated at the time that they did not desire any more children and did not give birth between surveys, $59 \%$, or 27 , reported at both time points that they did not want children; these 27 women represent $28 \%$ of the 95 women who did not have a son in 1998 and did not desire any more children.
}

TABLE 3. Of women not desiring children in 1998, percentage who desired no more in 2002, according to whether they had $a$ son in 1998 and gave birth between surveys

\begin{tabular}{lrl} 
Son and birth & N & $\begin{array}{l}\text { Desired no } \\
\text { more }\end{array}$ \\
\hline All & 1,179 & 79.9 \\
Birth & 568 & 78.7 \\
No birth & 611 & 81.0 \\
Had son & 1,084 & 82.1 \\
Birth & 519 & 81.3 \\
No birth & 565 & 82.8 \\
No son & & \\
Birth & 95 & 54.7 \\
No birth & 49 & 51.0 \\
& 46 & 58.7
\end{tabular}

give birth but no longer desired to stop childbearing, then only $43 \%$ of the women who had a son in 1998 can be said to have given consistent responses (not shown). ${ }^{*}$ By this definition, consistency was highest in Tamil Nadu (76\%) and Maharashtra (70\%), but relatively low in Bihar (39\%; not shown).

Among women who did not have a son in 1998 and said at that time that they did not desire any more children, consistency was even lower. Of these women, 55\% said in 2002 that they did not desire children, and only $28 \%$ both expressed this desire and did not give birth between surveys (not shown). ${ }^{\dagger}$ By this definition, the proportion of consistent responses was 51\% in Tamil Nadu, 15\% in Bihar and $7 \%$ in Maharashtra (not shown), although these findings are based on small sample sizes (41, 34 and 14, respectively).

Next, we examined whether women who had attained or surpassed their ideal family size in 1998 reported an explicit desire to stop childbearing at that time. Again, to understand how son preference might influence the association between the two indicators, we present findings separately for women who had a son at that time and those who did not. Among women with at least one son, 59\% had an implicit desire to stop childbearing (not shown) and 53\% had an explicit desire to do so (Table 4). The intention to stop childbearing was much less common among women who did not have a son: $28 \%$ had an implicit desire (not shown) and 16\% had an explicit desire. Note that the proportion of women who had attained or

\begin{tabular}{|c|c|c|c|c|c|c|}
\hline \multirow[t]{3}{*}{ Implicit desire } & \multicolumn{6}{|c|}{$\%$ desiring no more children } \\
\hline & \multicolumn{2}{|l|}{ All } & \multicolumn{2}{|l|}{ Son } & \multicolumn{2}{|c|}{ No son } \\
\hline & N & $\%$ & $\mathrm{~N}$ & $\%$ & $N$ & $\%$ \\
\hline All & 4,413 & 44.4 & 3,362 & 53.4 & 1,051 & 15.7 \\
\hline Yes & 2,268 & 72.5 & 1,972 & 78.5 & 296 & 32.4 \\
\hline No & 2,145 & 14.7 & 1,390 & 17.8 & 755 & 9.1 \\
\hline $\begin{array}{l}\text { Contingency } \\
\text { coefficient }\end{array}$ & \multicolumn{2}{|c|}{$0.502^{* *}$} & \multicolumn{2}{|c|}{$0.514^{* *}$} & \multicolumn{2}{|c|}{$0.227^{* *}$} \\
\hline
\end{tabular}

${ }^{*} \mathrm{p}<.05 .{ }^{* *} \mathrm{p}<.01 .{ }^{* * *} \mathrm{p}<.001$. Note: Sample limited to women who were not sterilized, whose husbands were not sterilized and who had at least one child in 1998. 
TABLE 5. Percentage of women who gave birth in 1998-2002, by implicit and explicit desire to stop childbearing, according to whether they had a son in 1998

\begin{tabular}{lllll|lll} 
Had son & All & \multicolumn{3}{l|}{ Implicit desire } & & \multicolumn{3}{|l}{ Explicit desire } \\
\cline { 3 - 7 } & & Yes & No & $\begin{array}{l}\text { Contingency } \\
\text { coefficient }\end{array}$ & Yes & No & $\begin{array}{l}\text { Contingency } \\
\text { coefficient }\end{array}$ \\
\hline All & $\mathbf{6 3 . 4}$ & $\mathbf{5 2 . 1}$ & $\mathbf{7 5 . 7}$ & $\mathbf{0 . 2 3 8 ^ { * * }}$ & $\mathbf{5 0 . 8}$ & $\mathbf{7 3 . 8}$ & $\mathbf{0 . 2 3 1 ^ { * * }}$ \\
No & 73.5 & 67.6 & 76.1 & $0.089^{*}$ & 59.0 & 76.4 & $0.144^{* *}$ \\
Yes & 60.5 & 49.7 & 75.5 & $0.252^{* *}$ & 50.0 & 72.3 & $0.222^{* *}$ \\
\hline
\end{tabular}

${ }^{*} \mathrm{p}<.05 .{ }^{* *} \mathrm{p}<.01 .{ }^{* * *} \mathrm{p}<.001$. Note: Sample limited to women who were not sterilized, whose husbands were not sterilized and who had at least one child in 1998.

surpassed their ideal family size was greater than the proportion who explicitly expressed the desire to stop childbearing; this was the case not only among both women who had a son and those who did not, but also in all three states (not shown). Moreover, the gap between the proportion with an implicit desire and that with an explicit desire was always larger among women who did not have a son. This seems logical: Women who have attained their ideal family size but not the sex composition of their children may be reluctant to express the explicit desire to stop childbearing. Among women without a son, the proportions with implicit and explicit desires to stop childbearing, respectively, were $21 \%$ and $10 \%$ in Bihar, $49 \%$ and $17 \%$ in Maharashtra, and 35\% and 30\% in Tamil Nadu.

In addition, the findings indicate that the two indicators were significantly associated with each other. In other words, the proportion of women expressing the explicit desire to stop childbearing was significantly higher among women who had attained or surpassed their ideal family size than among women who had not. For example, among women with at least one son, $79 \%$ of those with an implicit desire to stop childbearing also communicated an explicit desire to stop, compared with only $18 \%$ of those without an implicit desire. The contingency coefficient showing the degree of the association between the two preference indicators was much higher among women who had a son than among those without a son.

\section{Predictive Ability of Preference Indicators}

We examined whether women who in $1998 \mathrm{had}$ had an implicit or explicit desire to stop childbearing were more likely than women without such desire to give birth in the next four years, to report that their first birth during that time was unwanted and to be using a contraceptive

\begin{tabular}{|c|c|c|c|c|c|c|c|}
\hline \multirow[t]{2}{*}{ Had son } & \multirow[t]{2}{*}{ All } & \multicolumn{3}{|c|}{ Implicit desire } & \multicolumn{3}{|c|}{ Explicit desire } \\
\hline & & Yes & No & $\begin{array}{l}\text { Contingency } \\
\text { coefficient }\end{array}$ & Yes & No & $\begin{array}{l}\text { Contingency } \\
\text { coefficient }\end{array}$ \\
\hline All & 12.8 & 24.0 & 4.4 & $0.278^{* *}$ & 25.0 & 5.9 & $0.264^{* *}$ \\
\hline No & 3.1 & 6.5 & 1.8 & $0.120^{* *}$ & 7.6 & 2.5 & $0.015^{*}$ \\
\hline Yes & 16.4 & 27.7 & 5.7 & $0.284^{* *}$ & 26.8 & 7.9 & $0.247^{* *}$ \\
\hline
\end{tabular}

${ }^{*} \mathrm{p}<.05 .{ }^{* *} \mathrm{p}<.01 .{ }^{* * *} \mathrm{p}<-001$. Notes: Sample limited to women who were not sterilized, whose husbands were not sterilized and who had at least one child in 1998. If a woman had multiple births between surveys, wantedness was assessed only for the first birth. method in 2002. We restricted each analysis to nonsterilized women who had at least one child in 1998, and present findings according to whether women had a son at that time.

- Fertility. The proportion of women who gave birth between the two surveys was greater among women without a son than among those with at least one son $(74 \%$ vs. $61 \%$; Table 5). In both groups, having an implicit or explicit desire to stop childbearing was associated with reduced levels of fertility. For example, among women who had a son, $50 \%$ of those with the implicit desire to stop childbearing gave birth, compared with $76 \%$ of those without such a desire. Findings were roughly similar for the explicit desire to stop childbearing. For both preference indicators, the gap in fertility was larger among women who had a son in 1998 than among those without a son. However, in the latter group, the contingency coefficient was greater-thus suggesting better predictive value-for explicit desire than for implicit desire.

- Unwanted births. Among women who had a birth between the two surveys, those who had expressed a desire to stop childbearing in 1998, either implicitly or explicitly, were more likely than women without such desire to report that the first birth they had during that period was unwanted (Table 6). For example, 24\% of women with an implicit desire to stop childbearing described their first birth in the intersurvey period as unwanted, compared with only $4 \%$ of those without such desire. The contingency coefficients were greater among women with a son than among women without a son; similarly, the coefficients for implicit desire were greater than those for explicit desire.

- Contraceptive use. The two indicators were also associated with contraceptive behavior (Table 7). However, the pattern of this relationship was slightly different than that observed for fertility. For both indicators, the ability to predict contraceptive use was better for women without a son than for those with a son. For example, among women who did not have a son in 1998, $43 \%$ of those who had explicitly said they desired no more children were using a method in 2002, compared with $25 \%$ of women who had not said they desired to stop childbearing. The gap was smaller (39\% vs. $27 \%$ ) among women who had a son.

\section{DISCUSSION}

Our findings show that for each fertility preference indicator, women's responses at two points of time were largely consistent with each other. Moreover, the two indicators were related to each other: A woman who had an implicit desire to stop childbearing was likely to have explicitly expressed a desire to do so. Both preference indicators can be used fruitfully to predict future fertility; women who have attained or surpassed their ideal family size, or who have explicitly expressed a desire to have no more children, are less likely than other women to give birth in the future.

However, the two preference indicators are not identi- 
cal. The proportion of women with the implicit desire to stop childbearing was higher than the proportion who explicitly said they wanted to stop childbearing. In addition, because implicit desire is assessed using a measure of family size preference, it is less influenced than explicit desire by the sex composition of the family's children. Women are more likely to express the explicit desire to stop childbearing when they are satisfied with both the size and sex composition of their family. Moreover, the ability of the indicators to predict fertility is strongly influenced by the preference for (and hence the presence of) sons. In this study, among women who did not have a son, $68 \%$ of those with the implicit desire to stop childbearing subsequently gave birth, compared with 59\% of those with the explicit desire to stop. However, among women who had a son, the proportion of women who gave birth was nearly identical (50\%) in the two groups.

Factors other than sex preference may influence the preference indicators as well, including economic constraints and child mortality. It is difficult to ascertain, however, which preference indicator is more influenced by these and other factors.

Although the implicit desire to stop childbearing was consistent between the two surveys, our findings suggest that some women engaged in rationalization. Women who had had an implicit desire to stop childbearing at the first time point, but whose family size increased during the intersurvey period, tended to report a higher ideal family size at the second time point than they had earlier. The consistency of the second preference indicator, explicit desire for more children, was somewhat difficult to measure, as it is intimately linked with the fertility behavior of women during the intersurvey period. Consistency in this sense was low: Among women who said in 1998 that they desired to stop childbearing, only $43 \%$ of those who had a son, and $28 \%$ of those who did not, both expressed the same desire in 2002 and also did not give birth between surveys. Consistency was substantially higher in Tamil Nadu and Maharashtra than it was in Bihar.

When fertility is declining, it will often be lower than intended fertility. This was observed, for example, in a study of the U.S. population in $1970 .^{3}$ Although fertility has been declining in India, particularly in Tamil Nadu and Maharashtra, actual fertility has been greater than intended fertility. In fact, the gap between the percentage of women who gave birth and the percentage who would have given birth if they were consistent with their fertility intention was 21\% in Bihar, 18\% in Maharashtra and 7\% in Tamil $\mathrm{Nadu}$ (not shown). One reason for this mismatch, again, is the existence of son preference: The desire to have a son impels women to deviate from their stated intention of not having additional children.

Moreover, women in India often have a subordinate role in making fertility decisions. Unfortunately, no information was available for our sample on the fertility desire of husbands; however, it is likely that husbands and wives differ in their reproductive desires and behaviors, ${ }^{27}$ and
TABLE 7. Percentage of women who were using family planning in 2002, by implicit and explicit desire to stop childbearing, according to whether they had a son in 1998

\begin{tabular}{lllll|lll} 
Had son & All & \multicolumn{4}{l|}{ Implicit desire } & \multicolumn{2}{l}{ Explicit desire } \\
\cline { 3 - 8 } & & Yes & No & $\begin{array}{l}\text { Contingency } \\
\text { coefficient }\end{array}$ & Yes & No & $\begin{array}{l}\text { Contingency } \\
\text { coefficient }\end{array}$ \\
\hline All & $\mathbf{3 2 . 3}$ & $\mathbf{3 6 . 2}$ & $\mathbf{2 7 . 9}$ & $\mathbf{0 . 0 8 8 ^ { * * }}$ & $\mathbf{3 8 . 9}$ & $\mathbf{2 6 . 6}$ & $\mathbf{0 . 1 3 0 ^ { * * }}$ \\
No & 28.1 & 41.3 & 22.3 & $0.191^{* *}$ & 43.1 & 24.9 & $0.152^{* *}$ \\
Yes & 33.5 & 35.4 & 30.7 & $0.049^{* *}$ & 38.5 & 27.4 & $0.116^{* *}$ \\
\hline
\end{tabular}

${ }^{*} \mathrm{p}<.05 .{ }^{* *} \mathrm{p}<.01 .{ }^{* * *} \mathrm{p}<.001$. Note: Sample limited to women who were not sterilized, whose husbands were not sterilized and who had at least one child in 1998.

these differences may assist in explaining the apparent anomaly between women's fertility desires and their childbearing. The reluctance of many individuals in India to accept sterilization-the mainstay of the Indian family planning program, despite the recent policy shift toward emphasizing the use of other methods-and apathy regarding the use of spacing methods may also contribute to this incongruity by increasing the likelihood of unwanted fertility.

The two preference indicators are also useful in predicting contraceptive use. The predictive value was greater for women who did not have a son than for women who did have one. Moreover, the effectiveness of the indicators is influenced by prevailing fertility norms. In a population where the norm is to have two children and family planning is widespread, women with unmet need for contraception tend to be a select group: They are less likely than other women to have the urge to use contraceptives, either because they feel they cannot have children, or they have strong health-related or other reasons for not using a method. ${ }^{28}$ Among these women, the preference indicators may have less predictive value.

One important objective of a family planning program is to lessen the extent of unwanted fertility. The assessment of unwanted fertility has been a sensitive issue. Measuring unwanted fertility using prospective preference indicators-that is, the implicit or explicit expression of fertility intention-generally provides a higher estimate than if the assessment is done using retrospective reports on the wantedness of births or pregnancies. ${ }^{17,29}$ However, prospective preference indicators may provide a more accurate estimate of unwanted fertility than do retrospective reports. ${ }^{29}$ Future births to a woman who expresses a desire to stop childbearing are likely to be unwanted. Although many such births are not reported as unwanted in retrospective reporting, the proportion of births that are unwanted is nonetheless significantly higher among women who say they wish to stop childbearing than among women with no desire to stop childbearing. For example, in our study, one in four women (24\%) who expressed a desire to stop childbearing said that their next birth was unwanted, compared with one in 23 women (4.4\%) who did not have such a desire. India's family welfare program, therefore, would do well to monitor women who express a desire to stop childbearing; such women may require greater counseling to ensure that they use ap- 
propriate contraceptives and avoid unwanted fertility. It might be helpful if programs take into account whether these women have a son, as the likelihood that they will have an unwanted birth is much higher if they do.

Our findings indicate that both preference indicators are useful and can help immensely in improving the overall performance of the India's family planning program. It is difficult to choose between the two. Our analysis suggests that the desire for an additional child may be more effective than ideal family size in predicting future births, although the latter seems to have an edge in predicting unwanted births. As son preference declines, the value of the indicators in predicting the future fertility behavior of women should improve.

\section{REFERENCES}

1. McClelland GH, Family-size desires as measures of demand, in Bulatao RA and Lee RD, eds., Determinants of Fertility in Developing Countries, Vol. 1, New York: Academic Press, 1983, pp. 283-343.

2. Freedman R, Hermalin AI and Chang MC, Do statements about desired family size predict fertility? the case of Taiwan, 1967-1970, Demography, 1975, 12(3):407-416.

3. Westoff CF and Ryder NB, The predictive validity of reproductive intentions, Demography, 1977, 14(4):431-453.

4. Hermalin AI et al., Do intentions predict fertility? the experience in Taiwan, 1967-74, Studies in Family Planning, 1979, 10(3):75-95.

5. Foreit KG and Suh MH, The effect of reproductive intentions on subsequent fertility among low-parity Korean women, 1971-1976, Studies in Family Planning, 1980, 11(3):91-104

6. Nair NK and Chow LP, Fertility intentions and behavior: some findings from Taiwan, Studies in Family Planning, 1980, 11(7-8):255-263.

7. Thomson E, McDonald E and Bumpass LL, Fertility desires and fertility: hers, his and theirs, Demography, 1990, 27(4):579-588.

8. De Silva WI, Consistency between reproductive preferences and behavior: the Sri Lankan experience, Studies in Family Planning, 1991, 22(3): 188-197.

9. Tan PC and Tey NP, Do fertility intentions predict subsequent behavior? evidence from Peninsular Malaysia, Studies in Family Planning, 1994, 25(4):222-231.

10. Bankole A, Desired fertility and fertility behaviour among the Yoruba of Nigeria: a study of couple preferences and subsequent fertility, Population Studies, 1995, 49(2):317-328.

11. DaVanzo J, Peterson CE and Jones NR, How well do desired fertility measures for wives and husbands predict subsequent fertility? evidence from Malaysia, Asia-Pacific Population Journal, 2003, 18(4):5-24.

12. Pritchett LH, Desired fertility and the impact of population policies, Population and Development Review, 1994, 20(1):1-55.

13. Westoff CF and Bankole A, Unmet need: 1990-1994, DHS Comparative Studies, Calverton, MD, USA: Macro International, 1995, No. 16 .

14. Casterline JB and Sinding SW, Unmet need for family planning in developing countries and implications for population policy, Population and Development Review, 2000, 26(4):691-723.

15. Lightbourne R, Reproductive preferences and behavior, in: Cleland J, Scott C and Whitelegge D, eds., The World Fertility Survey: An Assessment, Oxford, UK: Oxford University Press, 1987, pp. 838-861.

16. Westoff CF, Reproductive preferences: a comparative view, DHS Comparative Studies, Columbia, MD, USA: Macro International, 1991 No. 3 .

17. Koenig MA et al., Do current measurement approaches underestimate levels of unwanted childbearing? evidence from rural India, Population Studies, 2006, 60(3):243-256

18. Bongaarts J, The measurement of wanted fertility, Population and Development Review, 1990, 16(3):487-506.
19. Vlassoff C, Fertility intentions and subsequent behavior: a longitudinal study in rural India, Studies in Family Planning, 1990, 21(4):216-225

20. International Institute for Population Sciences (IIPS) and The Johns Hopkins University, Quality of Care in Indian Family Planning Programme and Reproductive Behaviour of Women in Four Indian States: A Follow-Up Study of NFHS-2, Mumbai, India: IIPS, 2005.

21. IIPS and ORC Macro, National Family Health Survey (NFHS-2), India, 1998-99: Maharashtra, Mumbai, India: IIPS, 2001.

22. IIPS and ORC Macro, National Family Health Survey (NFHS-2), India, 1998-99: Tamil Nadu, Mumbai, India: IIPS, 2001.

23. IIPS and ORC Macro, National Family Health Survey (NFHS-2), India, 1998-99: Bihar, Mumbai, India: IIPS, 2001

24. Arnold F, Kishor S and Roy TK, Sex-selective abortions in India, Population and Development Review, 2002, 28(4):759-785.

25. Demeny P, Social science and population policy, Population and Development Review, 1988, 14(3):451-479.

26. Bankole A and Westoff CF, The consistency and validity of reproductive attitudes: evidence from Morocco, Journal of Biosocial Science, 1998, 30(4):439-455

27. Unisa S, Shekhar S and Roy TK, Husband-wife agreement on fertility goals: a study of three selected districts from Bihar and Uttar Pradesh, in: Roy TK, Guruswamy M and Arokiasamy P, eds., Population, Health and Development in India: Changing Perspectives, New Delhi: Rawat Publications, 2004

28. Mohanty SK et al., Programmatic implications of meeting the unmet need for contraception: a longitudinal study in rural India, Asian Population Studies, 2009 (forthcoming).

29. Casterline JB and El-Zeini LO, The estimation of unwanted fertility, Demography, 2007, 44(4):729-745.

\section{RESUMEN}

Contexto: El tamaño ideal de la familia y el deseo de tener un hijo adicional son los indicadores de preferencia de fecundidad más comúnmente usados. Sin embargo, se sabe poco acerca de la consistencia en el tiempo de las respuestas de cada medida, la consistencia entre los dos indicadores o el valor predictivo de estos indicadores en India.

Método: Se analizaron los datos de la Encuesta Nacional de Salud Familiar 1998-1999 y de una encuesta de seguimiento conducida cuatro años después con las mismas mujeres para determinar la consistencia de los dos indicadores de preferencia de fecundidad (tanto a través del tiempo como entre indicadores); así como para determinar si las respuestas de línea de base están asociadas con la subsiguiente fecundidad, los nacimientos no deseados y el uso de anticonceptivos.

Resultados: La proporción de las mujeres cuyas respuestas sobre la medida del tamaño ideal de la familia fueron consistentes en las dos encuestas, fue alta en Tamil Nadu (74\%) y Maharashtra (69\%) pero más baja en Bihar (38\%). Ochenta $y$ dos por ciento de las mujeres que dijeron explícitamente en 1998 que no deseaban más hijos respondieron de manera idéntica en 2002, aunque cerca de la mitad de esas mujeres dio a luz en el período entre las dos encuestas. Los dos indicadores se asociaron el uno con el otro: entre las mujeres con al menos un hijo varón, $79 \%$ de las que habían alcanzado o sobrepasado el tamaño ideal de su familia, dijeron que no deseaban más hijos, comparado con el 18\% de quienes no lo habian alcanzado. Ambos indicadores predijeron la fecundidad futura, los nacimientos no deseados y el uso de anticonceptivos, especial- 
mente entre mujeres que tenían un hijo varón.

Conclusión: Ambos indicadores son útiles para comprender el comportamiento futuro en materia de la fecundidad. Conforme la prevalencia de la preferencia por el hijo varón desciende en India, es probable que mejore la capacidad predictiva de los indicadores.

\section{RÉSUMÉ}

Contexte: Le nombre idéal d'enfants et le désir d'en avoir encore un sont les deux indicateurs de préférence de fécondité les plus utilisés. La constance dans le temps des réponses à chaque mesure, celle des deux indicateurs l'un par rapport à l'autre et la valeur prédictive de ces indicateurs ne sont cependant guère documentées en Inde.

Méthode: Les données longitudinales de l'enquête nationale de 1998-1999 sur la santé familiale et d'une enquête de suivi menée quatre ans plus tard ont été analysées afin de déterminer, d'une part, la constance des deux indicateurs de préférence de fécondité (dans le temps et d'un indicateur à l'autre) et, d'autre part, l'association ou non entre les réponses de base et la fécondité ultérieure, les naissances non désirées et la pratique de la contraception.

Résultats: La proportion des femmes dont les réponses relatives à la mesure du nombre idéal d'enfants sont constantes dans les deux enquêtes s'est avérée élevée dans les états de Nadu (74\%) et de Maharashtra (69\%), mais plus faible dans celui de Bihar (38\%). Quatre-vingt-deux pour cent des femmes ayant explicitement déclaré ne plus désirer d'enfants en 1998 ont répondu de même en 2002, bien qu'environ la moitié de ces femmes aient accouché dans l'intervalle. Les indicateurs se sont révélés associés l'un à l'autre: parmi les femmes mères d'au moins un fils, 79\% de celles qui avaient atteint ou dépassé leur nombre d'enfants idéal ont déclaré ne plus désirer en avoir, par rapport à $18 \%$ des autres. Les deux indicateurs se sont révélés prédictifs de fécondité future, naissances non désirées et pratique contraceptive, surtout parmi les femmes qui avaient un fils.

Conclusion: Les deux indicateurs sont utiles à la compréhension du comportement de fécondité futur. À mesure du déclin de la préférence des enfants de sexe masculin en Inde, la capacité prédictive des indicateurs devrait s'améliorer.

\section{Acknowledgments}

The authors thank the Bill and Melinda Gates Institute for Population and Reproductive Health, The Johns Hopkins University and the David and Lucile Packard Foundation for their financial support.

Author contact: rksinha@iips.net

\section{CALL FOR PAPERS}

\section{Maternal Mortality}

The 2000 Millennium Summit set the reduction of maternal mortality as one of eight millennium development goals, with the target of reducing the 1990 maternal mortality ratio by $75 \%$ by 2015 . The causes of maternal mortality are well-known, as are preventive measures and treatments. Yet by 2005 , the global ratio had declined by only $5 \%$, with a wide gap between developed and developing countries (decreases of $24 \%$ and $7 \%$, respectively). What factors influence mortality levels? What interventions might make a difference in low-resource settings? What concrete actions are needed - whether at the global, national or local level-to make progress in this neglected area? These are among the questions we hope to address in the December 2009 special issue of International Family Planning Perspectives on maternal mortality. We will consider commentaries as well as submissions based on either qualitative or quantitative research that have clear implications for programs or policies.

To be eligible for the special issue, submissions must be received by March 31,2009. Authors should follow the journal's style, as detailed in the Guidelines for Authors, which can be found at $<$ http://www.guttmacher.org/guidelines/guidelines_ifpp.html>.

To submit a manuscript, go to <http://mc.manuscriptcentral.com/ifpp > and follow the instructions for uploading your paper and cover letter. If using Manuscript Central is not possible, please e-mail electronic files for your article to Sandhya Ramashwar at sramashwar@guttmacher.org.The subject line should say "Non-MC Submission."

\section{Deadline: March 31, 2009}

